Research Article

\title{
Pharmacokinetic Herb-Drug Interaction between Hibiscus sabdariffa Calyces Aqueous Extract and Captopril in Rats
}

\author{
Shinta Ayu Nurfaradilla, ${ }^{1}$ Fadlina Chany Saputri $\left(\mathbb{D},{ }^{2}\right.$ and Yahdiana Harahap ${ }^{3}{ }^{3}$ \\ ${ }^{1}$ Graduate Program, Faculty of Pharmacy, Universitas Indonesia, Kampus UI, Depok 16424, Indonesia \\ ${ }^{2}$ Laboratory of Pharmacology, Faculty of Pharmacy, Universitas Indonesia, Kampus UI, Depok 16424, Indonesia \\ ${ }^{3}$ Laboratory of Bioavailability and Bioequivalency, Faculty of Pharmacy, Universitas Indonesia, Kampus UI, \\ Depok 16424, Indonesia
}

Correspondence should be addressed to Fadlina Chany Saputri; fadlina.chany@farmasi.ui.ac.id

Received 1 December 2019; Revised 8 April 2020; Accepted 15 May 2020; Published 17 June 2020

Academic Editor: Evan P. Cherniack

Copyright (c) 2020 Shinta Ayu Nurfaradilla et al. This is an open access article distributed under the Creative Commons Attribution License, which permits unrestricted use, distribution, and reproduction in any medium, provided the original work is properly cited.

\begin{abstract}
Hibiscus sabdariffa L. (Malvaceae) is a traditional medicinal herb widely consumed as a beverage ("hibiscus tea"), and its global popularity is expanding due to health benefits such as blood pressure and cholesterol control. Previous studies showed that Hibiscus sabdariffa is coadministered with antihypertensives and antihyperlipidemics, thus predisposing herb-drug interactions. We investigated the pharmacokinetic interaction between $H$. sabdariffa L. aqueous extract and captopril, a frequently prescribed antihypertensive. In this study, chemical profile of $H$. sabdariffa L. aqueous extract was identified using HPLC system equipped with a DAD detector at $360 \mathrm{~nm}$ and $520 \mathrm{~nm}$. The male Sprague Dawley rats were divided into two groups of six rats. Group I received a single dose of captopril suspension $(4.5 \mathrm{mg} / 200 \mathrm{~g}$ body weight (BW) orally (p.o.)) while group II received $H$. sabdariffa L. aqueous extract $(60 \mathrm{mg} / 200 \mathrm{~g}$ BW; p.o.) daily for two weeks prior to the same captopril dose. Multiple blood samples were collected at predetermined times after captopril administration and the plasma concentration was analyzed using ultrahighpressure liquid chromatography-tandem mass spectrometry. Chemical profiling of the $H$. sabdariffa L. aqueous extract showed that the extract contains chlorogenic acid, myricetin 3-arabinogalactoside, 5-O-caffeoylshikimic acid, quercetin 3-rutinoside, delphinidin 3-sambubioside, and cyanidin 3-sambubioside. Ingestion of the extract significantly reduced the captopril area under the curve (AUC) $\left.)_{0-\mathrm{t}}(0.1745(0.1254-0.2429)), \mathrm{AUC0}_{-\infty}(0.1734(0.1232-0.2442))\right]$, and peak plasma concentration $(0.2119$ (0.1337-0.3359)) (geometric mean ratio of the coadministration group to the captopril group (90\% CI)). The geometric mean ratios were falling outside the $90 \% \mathrm{CI}$ of $0.8-1.25$ bioequivalent range. Conversely, $H$. sabdariffa $\mathrm{L}$. extract increased the apparent total body clearance $(\mathrm{Cl} / \mathrm{F}, 0.0257 \pm 0.0115$ vs. $0.1418 \pm 0.0338 \mathrm{~mL} / \mathrm{h} \cdot \mathrm{kg}$ ) and the apparent volume of distribution $(\mathrm{Vd} / \mathrm{F}$, $0.0541 \pm 0.0226$ vs. $0.3205 \pm 0.0790 \mathrm{~mL} / \mathrm{kg}$ ). This study indicated that coadministration of $H$. sabdariffa L. aqueous extract could change the pharmacokinetic profile of captopril; therefore, its coadministration should be avoided.
\end{abstract}

\section{Introduction}

Hibiscus sabdariffa L. (Malvaceae) is an herbaceous shrub grown in tropical areas such as India, Malaysia, Africa, Australia, Florida, the Philippines, and Indonesia [1]. Beverages made from $H$. sabdariffa L. (variously referred to as "sour tea" or "hibiscus tea") are consumed in many regions of the world and extracts have been used as traditional medicines in numerous cultures [2-4]. The consumption of hibiscus tea is growing in popularity owing to accumulating evidence that it can safely reduce blood pressure and serum cholesterol, two major risk factors for cardiovascular disease [3]. Furthermore, benefits against cancer, excess weight, liver disease, infertility, and diabetes have been proposed [1,4]. A survey by Showande et al. [5] on staff and students at the University of Ibadan in Africa found that some respondents often consume sour tea with pharmaceuticals such as antibiotics, antihypertensives, antipsychotics, antihyperlipidemics, and antiretrovirals. It is therefore important to determine whether there are herb-drug 
interactions that may interfere with the primary drug activity. Indeed, previous preclinical and clinical studies showed that ingestion of $H$. sabdariffa L. extract with conventional pharmaceuticals such as acetaminophen, chloroquine, hydrochlorothiazide, and simvastatin can change the pharmacokinetics profile of the primary drug, potentially affecting the treatment efficacy [5-9].

Animal models, particularly rodents, are widely used in preclinical studies and have become a valuable tool for providing information on the efficacy, safety, and mechanism of action of various drugs and compounds used in treatment $[10,11]$. The findings of animal research could traditionally be projected to humans [10]. One of the reasons of using animals in biomedical research is due to its similarities to human, particularly its similarity in anatomical basis and physiological functions with humans [11].

In Indonesia, $H$. sabdariffa L. is often consumed with angiotensin-converting enzyme inhibitor captopril, a frequently prescribed antihypertensive [12]; however, a previous study showed that coadministration of $H$. sabdariffa does not influence the antihypertensive potency of captopril in a $2 \mathrm{~K} 1 \mathrm{C}$ rat hypertension model [13]. To our knowledge, there is no available information regarding pharmacokinetic interactions between captopril and $H$. sabdariffa. Therefore, this study examined changes in the captopril pharmacokinetic characteristics in rats following prolonged administration of $H$. sabdariffa L. aqueous extract.

\section{Materials and Methods}

2.1. Chemical and Herbal Extract. Reference standard captopril, propranolol hydrochloride (used as the internal standard (IS)), and the derivatization reagent 2-4-dibromoacetophenone were purchased from Sigma-Aldrich (Singapore). HPLC grade acetonitrile (ACN) and formic acid were purchased from Merck Chemicals (Germany). The calyces of $H$. sabdariffa $\mathrm{L}$ were procured from the Research Institute for Medicinal and Aromatic Plants (Bogor, Indonesia) and identified by the Indonesian Institute of Sciences Center for Plant Conservation Botanic Garden (Bogor, Indonesia; reference number B-2306/IPH.3/KS/VII/2018). Extraction was performed by maceration at $50^{\circ} \mathrm{C}$ for $6-7$ hours (ratio between simplicia and water was $1: 6$ ). The aqueous extract was evaporated until it forms the honey-like form and then stored at $4^{\circ} \mathrm{C}-10^{\circ} \mathrm{C}$. The yield of extract was $35.4 \%$. This procedure was performed at the Research Institute for Medicinal and Aromatic Plants. The captopril sample used for pharmacokinetic measurements was obtained from $25 \mathrm{mg}$ generic tablets which were marketed in Indonesia.

2.2. Chemical Profile of Hibiscus sabdariffa Extracts. Chemical profile of $H$. sabdariffa L. aqueous extract was identified using a high-pressure performance chromatography (HPLC) system (Agilent Technologies 1200 Series HPLC-0053, Germany) equipped with a diode-array detector (DAD; serial no. DE60555816). Compounds separation was performed using a reversed phase C18 column
(Inertsil ODS-3; $5.0 \mu \mathrm{m}, 4.6 \times 150 \mathrm{~mm}$; Japan) as the stationary phase and two gradient programs of the mobile phase running at a flow rate of $0.5 \mathrm{~mL} / \mathrm{min}$ [14]. Gradient program 1 contained a mixture of solution A (1\% formic acid: ACN $(10: 90)$ ) and solution B (ACN) while gradient program 2 contained a mixture of solution A (10\% formic acid in water) and solution $\mathrm{B}(\mathrm{ACN})$. Detections were performed at $360 \mathrm{~nm}$ for gradient program 1 and $520 \mathrm{~nm}$ for gradient program 2 . The injection volume for the sample was $20 \mu \mathrm{L}$.

2.3. Experimental Animals. Twelve adult male Sprague Dawley rats (approximately 3 months old) weighing 150-250 g were obtained from Bogor Agricultural University (IPB; Bogor, Indonesia). The rats were housed under a controlled ambient temperature $\left(25 \pm 5{ }^{\circ} \mathrm{C}\right)$ and a $12 \mathrm{~h} \mathrm{:12} \mathrm{h}$ light: dark cycle with free access to food and water. The bedding for each cage was replaced thrice a week. All animal care and experimental procedures were prepared according to Animal (Scientific Procedures) Act 1986 and were reviewed as well as approved by the Ethics Committee of the Faculty of Medicine, Universitas Indonesia (Jakarta, Indonesia) under the reference number 0646/UN2.F1.ETIK/ 2018 .

2.4. Validation Method and Analysis of Captopril. Captopril was measured in the plasma using a modified ultrahigh-pressure liquid chromatography-tandem mass spectrometry (UPLC-MS/MS) method [15-18]. Chromatography was performed using a reversed phase C18 column (Acquity UPLC BEH Shield RP; $1.7 \mu \mathrm{m}, 2.1 \times 100 \mathrm{~mm}$; Waters, Milford, CT, USA) at a column temperature of $40^{\circ} \mathrm{C}$. A mixture of $0.1 \%$ formic acid and ACN was used as the mobile phase with the gradient elution profile shown in Table 1. Captopril was detected using a Xevo TQD mass spectrometer (Waters, USA) equipped with a positive electrospray ionization ion source in multiple reaction monitoring modes. The operational parameters for mass detection are presented in Table 2. Acquisition and integration of data were performed using MassLynx 4.1 SCN805 Software solution.

The stock solution of the reference standard captopril $(1000 \mathrm{mg} / \mathrm{L})$ was prepared by dissolving $10 \mathrm{mg}$ of the reference standard in $10 \mathrm{~mL}$ aquadest. The stock solution of propranolol (1000 mg/L, IS) was prepared by dissolving $10 \mathrm{mg}$ of the reference standard in $10 \mathrm{~mL}$ methanol: aquadest $(50: 50)$. The stock solution of 2-4-dibromoacethophenone $(520 \mathrm{mg} / \mathrm{L})$ was prepared by dissolving $5.2 \mathrm{mg}$ in $10 \mathrm{~mL}$ methanol. Quality control samples and calibration standards were prepared by diluting standard stock solutions with rat plasma. The captopril quality control samples were prepared at concentrations of 9,40 , and $80 \mathrm{ng} / \mathrm{mL}$, while the calibration standards were prepared at concentrations of $3,9,12,25,50,80$, and $100 \mathrm{ng} / \mathrm{mL}$.

The validation method in analysis of captopril was performed by examining the accuracy, precision, sensitivity, selectivity, matrix effect, carry over, and stability profiles of captopril according to EMA guidelines. 
TABLE 1: Gradient profile of the mobile phase used to analyze plasma captopril.

\begin{tabular}{lccc}
\hline Time $(\mathrm{min})$ & Flow rate $(\mathrm{mL} / \mathrm{minutes})$ & $0.1 \%$ Formic acid in aquadest $(\%)$ & Acetonitrile $(\%)$ \\
\hline 0 & 0.2 & 60 & 40 \\
1 & 0.2 & 10 & 90 \\
2 & 0.2 & 10 & 90 \\
2.5 & 0.2 & 60 & 40 \\
5 & 0.2 & 60 & 40 \\
\hline
\end{tabular}

TABLE 2: Operational parameters for mass spectrometry detection of captopril and propranolol.

\begin{tabular}{lc}
\hline Parameter & Value \\
\hline Cone (V) & Captopril, 32; propranolol, \\
& 22 \\
Collision energy (V) & Captopril, 36; propranolol, \\
Mode of analysis & 18 \\
Ion transition for captopril (Da) & Positive \\
$\begin{array}{l}\text { Ion transition for propranolol (IS) } \\
\text { (Da) }\end{array}$ & $\mathrm{m} / \mathrm{z} 414.01 / 216.082$ \\
\hline
\end{tabular}

2.5. Preparation of Plasma Sample. Blood samples were collected in EDTA tubes and centrifuged at 5,000 rpm for 10 min to obtain plasma. For derivatization of plasma captopril, a plasma sample $(180 \mu \mathrm{L})$ was first mixed with $20 \mu \mathrm{L}$ of $520 \mathrm{ppm}$ 2-4-dibromoacetophenone stock solution and $20 \mu \mathrm{L}$ of $5 \%$ ammonia solution, vortexed for 30 seconds, and incubated at room temperature for $30 \mathrm{~min}$. The derivatization reaction was stopped by adding $20 \mu \mathrm{L}$ of $15 \%$ formic acid. Then, $20 \mu \mathrm{L}$ of $1 \mathrm{mg} / \mathrm{L}$ propranolol (IS) was added to the mixture and vortexed for $30 \mathrm{~s}[17,18]$. Plasma proteins were precipitated by adding $600 \mu \mathrm{L}$ ice-cold $\mathrm{ACN}$, vortexing for $30 \mathrm{~s}$, and centrifuging at $12,000 \mathrm{rpm}$ for $5 \mathrm{~min}$. Supernatant samples $(600 \mu \mathrm{L})$ were evaporated by nitrogen gas flowing at $60^{\circ} \mathrm{C}$ for $15 \mathrm{~min}$. The residue was dissolved in $300 \mu \mathrm{L}$ of the mobile phase and transferred to an autosampler vial. The injection volume for UPLC-MS/MS was $5 \mu \mathrm{L}$.

2.6. Pharmacokinetic Interaction Study. The experimental animals were divided randomly and blindly into two groups ( $n=6 /$ group). Group I received single dose captopril suspension $(4.5 \mathrm{mg} / 200 \mathrm{~g} \mathrm{BW}$; p.o.) while group II received $H$. sabdariffa L. aqueous extract ( $60 \mathrm{mg} / 200 \mathrm{~g} \mathrm{BW}$; p.o.) daily for two weeks at morning and a single captopril dose $(4.5 \mathrm{mg} /$ $200 \mathrm{~g} \mathrm{BW}$; p.o.) immediately after the last extract administration. The animals were anaesthetized before blood collection process. Blood samples (approximately $0.36 \mathrm{~mL}$ per sample) were obtained before captopril administration and 5 , $15,30,45,60,120,180,300,420$, and $600 \mathrm{~min}$ after administration. The loss of body fluid was compensated by administrating $1.0 \mathrm{~mL}$ saline solution (p.o.) every $30 \mathrm{~min}$. Plasma was then isolated from blood samples as described.

2.7. Data Analysis. The captopril pharmacokinetic parameters area under curve $\left(\mathrm{AUC}_{0-\mathrm{t}}\right.$ and $\left.\mathrm{AUC}_{0-\infty}\right)$, peak plasma concentration $(\mathrm{Cmax})$, time at peak plasma concentration (Tmax), half-life $\left(\mathrm{T}_{1 / 2}\right)$, apparent total body clearance $(\mathrm{Cl} / \mathrm{F})$, apparent volume of distribution $(\mathrm{Vd} / \mathrm{F})$, and elimination constant $(\mathrm{Ke})$ were estimated using PKSolver $^{\circledR}$ compartmental analysis software. All data are expressed as mean \pm standard deviation. Group means were compared by Mann-Whitney $U$ test using SPSS (v24.0). A $P<0.05$ (two-tailed) was considered statistically significant for all tests. Geometric mean ratios with 90\% confidence intervals (CI) for AUC and Cmax of the coadministration group versus the captopril group were calculated. Herb-drug interaction was established if the geometric mean ratios with $90 \% \mathrm{CI}$ for AUC and Cmax were outside of the bioequivalence range $(0.8-1.25)$.

\section{Results and Discussion}

3.1. Chemical Profile of Hibiscus sabdariffa Extracts. Separation and identification of polyphenols, HCA, and lactone were performed using gradient program 1 at $360 \mathrm{~nm}$, while anthocyanins were detected using gradient program 2 at $520 \mathrm{~nm}$ [13]. The chemical profile (Figure 1) showed that $H$. sabdariffa aqueous extracts contained chlorogenic acid (1), myricetin 3-arabinogalactoside (2), 5-O-caffeoylshikimic acid (3), quercetin 3-rutinoside (4), delphinidin 3sambubioside (5), and cyanidin 3-sambubioside (6). Anthocyanins were detected using a gradient elution with $10 \%$ formic acid and detection at $520 \mathrm{~nm}$ since the acid-base equilibrium state of this class is stable at acidic $\mathrm{pH}$ [14]. Among the compounds identified, delphinidin 3-sambubioside and cyanidin 3-sambubioside have been shown to inhibit angiotensin-converting enzyme while quercetin has been shown the vasodilator activity $[19,20]$.

3.2. Experimental Animal. All rats used in this experiment were weighted prior to treatment procedure. The weights of rats were in the range of $150-250 \mathrm{~g}(172.92 \pm 21.90)$. The rats were also in good health condition, which was shown by clear eyes, normal behaviour, and motoric movement.

3.3. Chromatography of Captopril. The chromatography system yielded shape peaks for propranolol and captopril derivatives, with retention times of 1.73 and $3.22 \mathrm{~min}$, respectively (Figure 2).

3.4. Linearity, Lower Limit of Quantification (LLOQ), and Accuracy and Precision. The captopril calibration curve was linear over the range $3-100 \mathrm{ng} / \mathrm{mL}(r=0.9998)$. The LLOQ was $3 \mathrm{ng} / \mathrm{mL}$ with a coefficient of variation (\%CV) of $14.38 \%$ and a $\%$ Diff between $-16.39 \%$ and $16.07 \%$. The within-run 


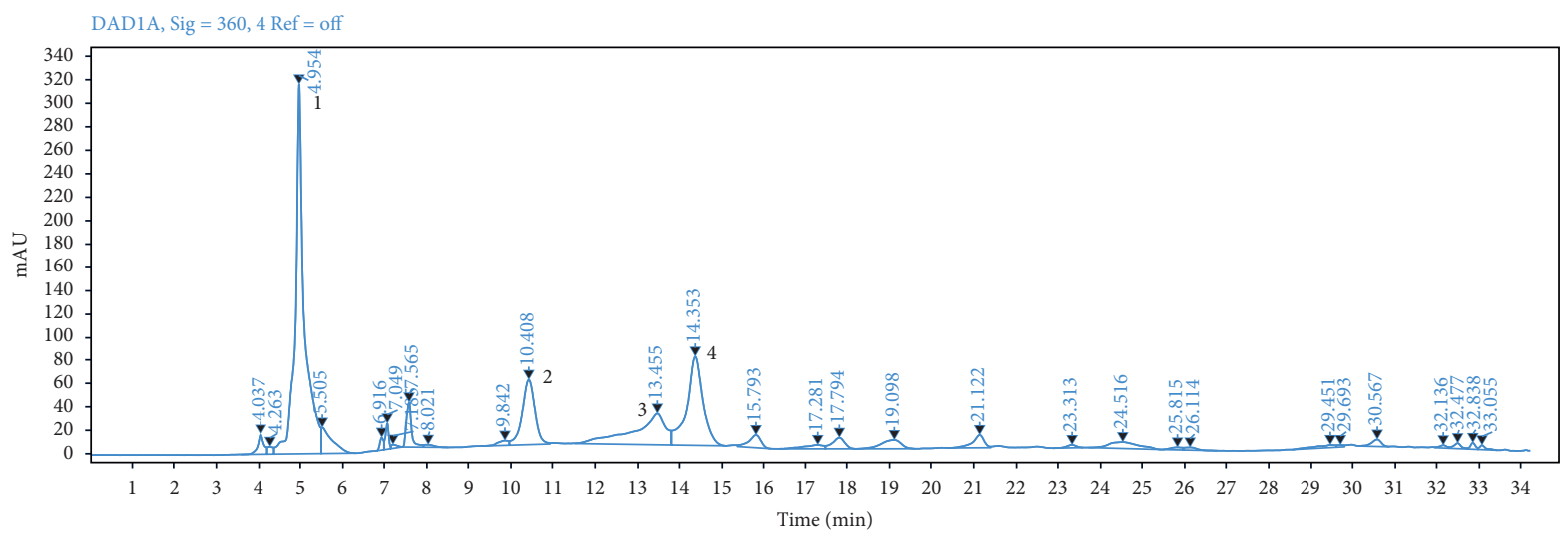

(a)

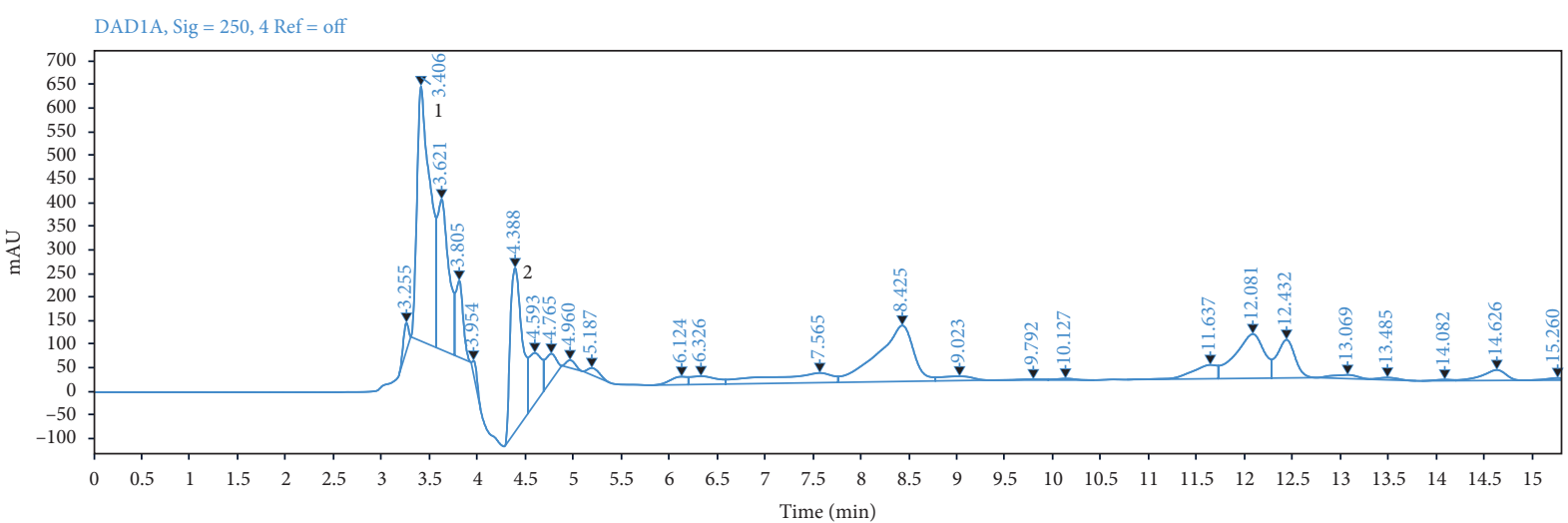

(b)

FIgURE 1: Chromatographic profile of Hibiscus sabdariffa L aqueous extract using the gradient programs described in methods. (a) UV chromatogram at $360 \mathrm{~nm}$ using gradient program 1. (b) UV chromatogram at $520 \mathrm{~nm}$ using gradient program 2.
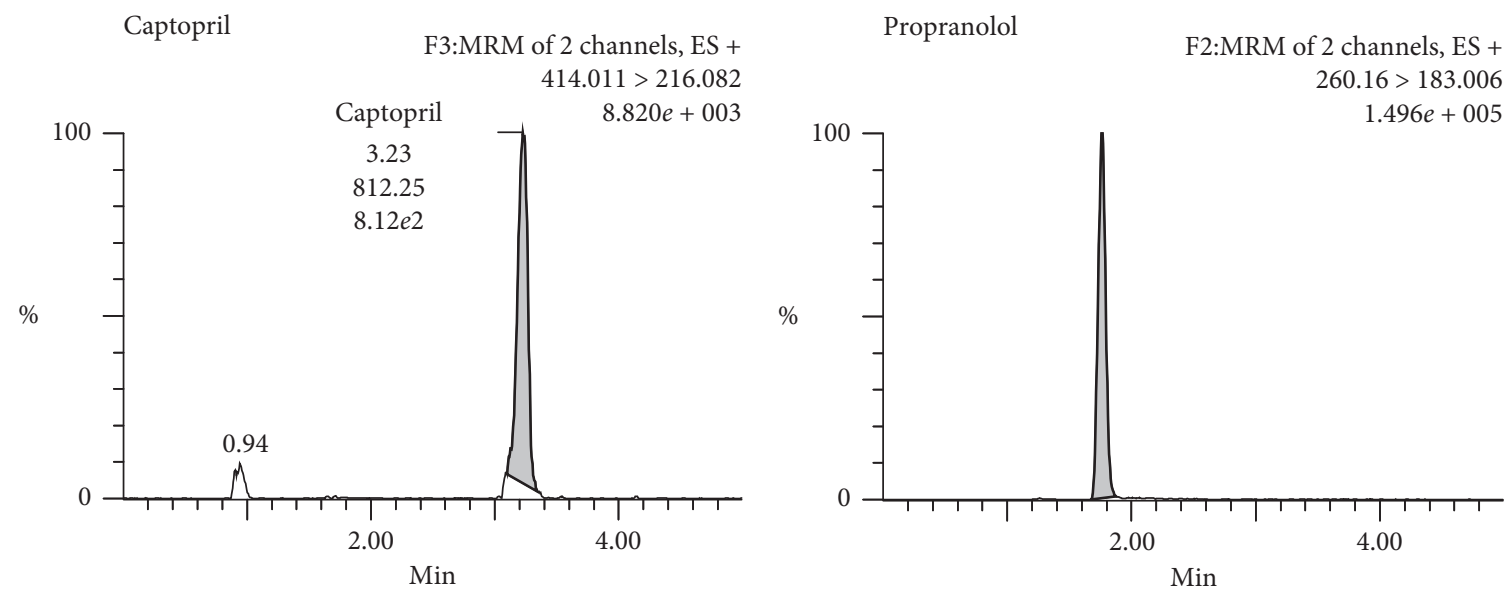

FIGURE 2: Chromatogram of derivate captopril and propranolol.

TABLE 3: Accuracy and precision of plasma captopril detection.

\begin{tabular}{|c|c|c|c|}
\hline Actual concentration $(\mathrm{ng} / \mathrm{mL})$ & Mean measured concentration \pm standard deviation $(\mathrm{ng} / \mathrm{mL})$ & $\% \mathrm{CV}$ & $\%$ Diff \\
\hline 3 & $3.05 \pm 0.44$ & 14.38 & 12.65 \\
\hline 9 & $9.65 \pm 1.00$ & 10.38 & 12.08 \\
\hline 40 & $38.74 \pm 4.14$ & 10.69 & 9.51 \\
\hline 80 & $76.36 \pm 1.19$ & 1.56 & 4.54 \\
\hline
\end{tabular}


accuracy and precision of captopril analysis ranged from $1.56 \%$ to $14.38 \%$ (Table 3 ).

3.5. Selectivity. In selectivity testing, six rats plasma was used. Selectivity testing was performed on LLOQ concentration and the interference value was compared to blank plasma solution. The results showed that the interference values of endogenous substances were within limit.

3.6. Carry over. The maximum of carry over value is $1.16 \%$ for captopril and $3.22 \%$ for propranolol. Those values were within the acceptance criteria for the analyte $(<20 \%)$ and the internal standard $(<5 \%)$.

3.7. Matrix Effect. Ion suppression was observed during matrix effect testing (0.97); however, the value is still within the acceptance criteria $(0.80-1.20)$.

3.8. Stability Test. The stability profiles of captopril were assessed in different storage conditions. Based on our study, the QCH and QCL solutions were stabile when stored in room temperature for $24 \mathrm{hrs}$, in autosamples for $24 \mathrm{hrs}$, and in freezer $\left(-25^{\circ} \mathrm{C}\right)$ for 7 days. The QCL and QCH solutions were also stabile after 3 cycles of freeze-thaw.

3.9. Pharmacokinetics Interaction Study. The mean captopril plasma concentration versus time curve is shown in Figure 3 and the pharmacokinetic parameters are listed in Table 4. Consumption of $H$. sabdariffa $\mathrm{L}$. aqueous extract for two weeks reduced the captopril $\mathrm{AUC}_{0-\mathrm{t}}(956.86 \pm 314.28$ vs. $162.35 \pm 41.00 \mathrm{ng} \cdot \mathrm{h} / \mathrm{mL}), \quad \mathrm{AUC}_{0-\infty} \quad(993.32 \pm 339.55$ vs. $166.72 \pm 41.82 \mathrm{ng} \cdot \mathrm{h} / \mathrm{mL})$, and $C \max (282.98 \pm 124.79$ vs. $60.02 \pm 28.84 \mathrm{ng} / \mathrm{mL}$ ) significantly (all $P<0.05$ ) and increased $\mathrm{Cl} / \mathrm{F}(0.0257 \pm 0.0115$ vs. $0.1418 \pm 0.0338 \mathrm{~mL} / \mathrm{h} \mathrm{kg})$ and $\mathrm{Vd} / \mathrm{F}(0.0541 \pm 0.0226$ vs. $0.3205 \pm 0.0790 \mathrm{~mL} / \mathrm{kg})$ significantly (both $P<0.05)$. Geometric mean ratios $(90 \% \mathrm{CI})$ for $\mathrm{AUC}_{0-\mathrm{t}}, \mathrm{AUC}_{0-\infty}$, and Cmax between coadminisration and captopril groups could be seen in Table 5 . The geometric mean ratio and $90 \%$ confidence intervals $(\mathrm{CI})$ of the coadministration group to the captopril group were 0.1745 (0.1254-0.2429) for $\mathrm{AUC}_{0-\mathrm{t}}, 0.1734(0.1232-0.2442)$ for $\mathrm{AUC}_{0-\infty}$, and $0.2119(0.1337-0.3359)$ for Cmax, respectively. Those geometric mean ratios of AUC and Cmax were not bioequivalent.

3.10. Effect of Coadministration of $H$. sabdariffa L Aqueous Extract on Pharmacokinetic Profile of Captopril. H. sabdariffa L. aqueous extract or sour tea is growing in popularity due to a variety of purposed health benefits, but several studies have reported that its consumption can alter the pharmacokinetic profiles and potential efficacies of prescribed medications [5-9]. Among the best described health benefits of $H$. sabdariffa $L$. is blood pressure control for hypertension, suggesting that many patients on conventional antihypertensives may also consume $H$. sabdariffa $\mathrm{L}$. extract $[3,5,12]$.
Administration of the extract was given two weeks prior to the administration of captopril since the extracts need time to induce the enzyme metabolizing captopril. Moreover, the study literature showed that two-week period of $H$. sabdariffa extract administration could produce the antihypertensive activity. In this study, we would like to determine whether coadministration of $H$. sabdariffa extract with captopril which is given in the same manner in a pharmacodynamics study could produce pharmacokinetic herb-drug interaction.

Captopril is an unstable and photolabile compound with a sulfhydryl group prone to dimerization and binding to various endogenous plasma molecules with sulfhydryl groups such as cysteine and glutathione [21, 22]. In this experiment, we used 2-4-dibromoacetophenone as a derivatization agent to prevent the sulfhydryl group in captopril from binding to plasma sulfhydryl groups. Ammonia was used during derivatization since the reaction is optimal at basic $\mathrm{pH}$. The reaction was then stopped by adding formic acid [17].

The chromatography system yielded sharp chromatograms for both derivate captopril and propranolol (the IS) within $5 \mathrm{~min}$ and a captopril LLOQ of $3 \mathrm{ng} / \mathrm{mL}$. The accuracy and precision of the captopril measurements were determined by five replicates of each quality control sample $(3,9$, 40 , and $80 \mathrm{ng} / \mathrm{mL}$ ), which yielded \%CV values of $1.56 \%-$ $14.38 \%$ and \% Diff values of less than $15 \%$. Thus, the chromatographic method was of sufficient reliability and reproducibility for captopril measurement within the analytical range [23]. The selectivity, carry over, and matrix effect tests also showed that the chromatographic method fulfills the acceptance criteria. Therefore, the developed method could be concluded as a valid method.

It is known that captopril absorption by the gut is influenced by the presence of food [21, 22]. Therefore, captopril was administered one hour after the final oral administration of $H$. sabdariffa L. However, the present study showed that two weeks of regular $H$. sabdariffa L. aqueous extract consumption reduced the AUC and peak plasma concentration of captopril suggesting reduced efficacy (Tables 4 and 5) and the geometric mean ratios were falling outside the bioequivalent range. There is no side effect observed after the treatment of captopril and Hibiscus sabdariffa aqueous extract. Previous herb-drug pharmacokinetic interaction studies on Hibiscus sabdariffa aqueous extract showed similar observation. Coadministration of the extract could increase the clearance of acetaminophen, reduce the AUC and Cmax of chloroquine, and increase the clearance as well as reduce the AUC of simvastatin $[4,7,8]$. However, the coadministration of Hibiscus sabdariffa aqueous extract with captopril does not influence the antihypertensive potency of captopril or its effects on biomarkers of the renin-angiotensin-aldosterone system (RAAS). The coadministration also does not negatively influence captopril action [13].

Comparing the results of this study and our previous study [13], we could not determine the exact mechanism of this herb-drug interaction. However, there are some hypotheses which could explain the interaction as follows: $H$. 


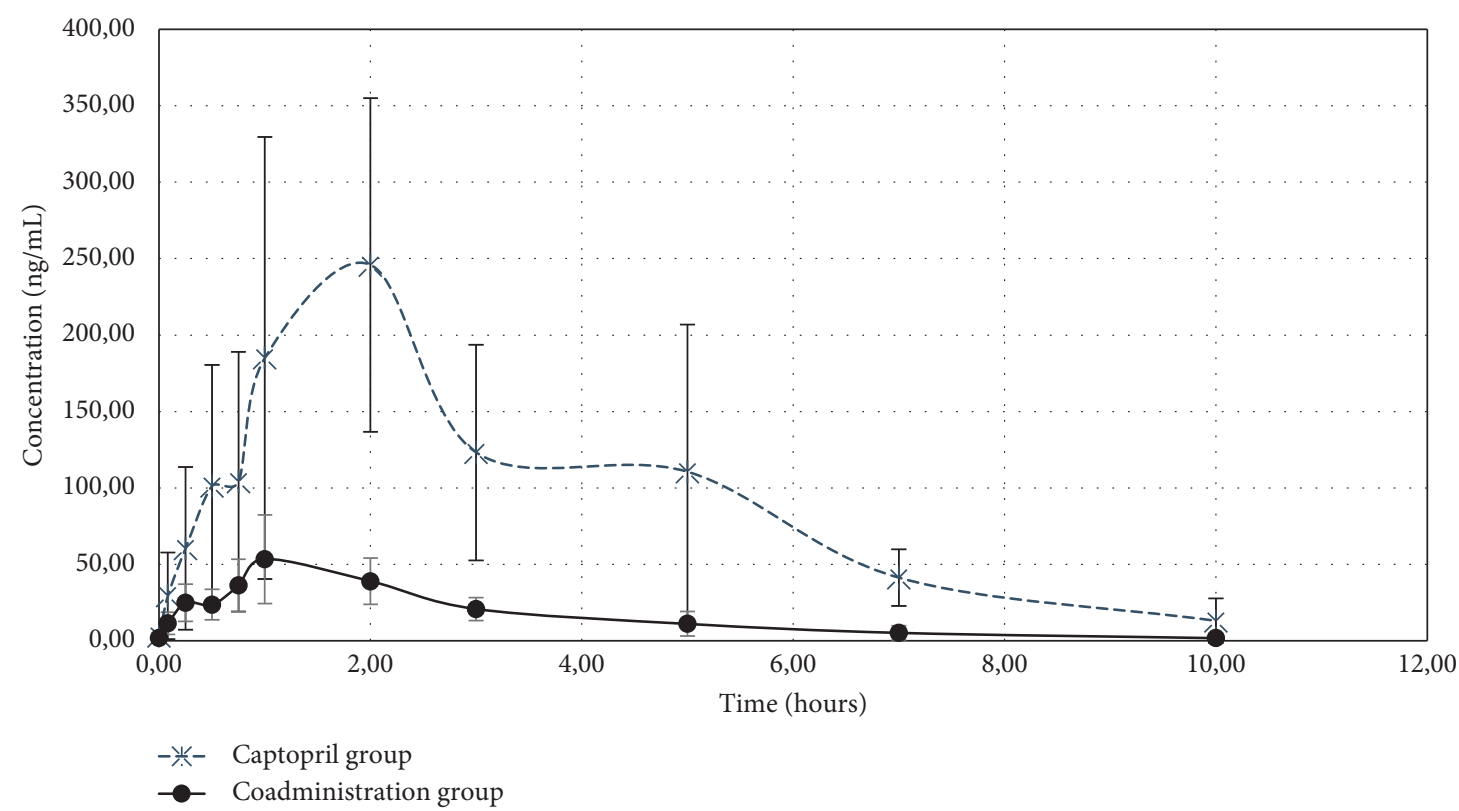

Figure 3: Mean plasma concentration vs. time curves of the captopril group and on coadministration with Hibiscus sabdariffa aqueous extract in rats.

TABle 4: Plasma pharmacokinetic profile of captopril and its coadministration with Hibiscus sabdariffa aqueous extract in rats.

\begin{tabular}{lcc}
\hline Parameter & Group I $(n=6)$ & Group II $(n=6)$ \\
\hline $\mathrm{AUC}_{0-\mathrm{t}}(\mathrm{ng} \mathrm{h} / \mathrm{mL})$ & $956.86 \pm 314.28$ & $162.35 \pm 41.00^{*}$ \\
$\mathrm{AUC}_{0-\infty}(\mathrm{ng} \mathrm{h} / \mathrm{mL})$ & $993.32 \pm 339.55$ & $166.73 \pm 41.82^{*}$ \\
$C_{\max }(\mathrm{ng} / \mathrm{mL})$ & $282.98 \pm 124.79$ & $60.02 \pm 28.84^{*}$ \\
$T_{\max }(\mathrm{h})$ & $2.17 \pm 1.47$ & $1.46 \pm 0.87$ \\
$T_{1 / 2}(\mathrm{~h})$ & $1.51 \pm 0.52$ & $1.58 \pm 0.25$ \\
$\mathrm{Cl} / \mathrm{F}(\mathrm{mL} / \mathrm{h} \cdot \mathrm{kg})$ & $0.0257 \pm 0.0115$ & $0.1418 \pm 0.0338^{*}$ \\
$\mathrm{Vd} / \mathrm{F}(\mathrm{mL} / \mathrm{kg})$ & $0.0541 \pm 0.0226$ & $0.3205 \pm 0.0790^{*}$ \\
$\mathrm{Ke}(1 / \mathrm{h})$ & $0.4907 \pm 0.1149$ & $0.4475 \pm 0.0597$ \\
\hline
\end{tabular}

Group I, captopril alone; group II, coadministration with Hibiscus sabdariffa extract; $\mathrm{AUC}$, area under the curve; $\mathrm{Cmax}, \mathrm{maximum}$ concentration; $\mathrm{Cl} / \mathrm{F}$, apparent total body clearance; $\mathrm{Vd} / \mathrm{F}$, apparent volume of distribution. ${ }^{*} P<0.05$.

TABLE 5: $90 \%$ CI for geometric mean ratios of $\mathrm{AUC}_{0-\mathrm{t}}, \mathrm{AUC}_{0-\infty}$, and $C_{\text {max }}$.

\begin{tabular}{lcccc}
\hline \multirow{2}{*}{ Parameter } & \multicolumn{2}{c}{ Geometric mean } & Geometric mean ratio* $^{*}$ & 90\% confidence interval $^{+}$ \\
& Group I & Group II & 0.1745 & $0.1254-0.2429$ \\
$\mathrm{AUC}_{0-\mathrm{t}}(\mathrm{ng} \mathrm{h} / \mathrm{mL})$ & 907.1936 & 158.3434 & 0.1734 & $0.1232-0.2442$ \\
$\mathrm{AUC}_{0-\infty}(\mathrm{ng} \mathrm{h} / \mathrm{mL})$ & 937.3462 & 162.5549 & 0.2119 & $0.1337-0.3359$ \\
$C_{\max }(\mathrm{ng} / \mathrm{mL})$ & 260.6754 & 55.2459 & \\
\hline
\end{tabular}

Group I, captopril alone; group II, coadministration with Hibiscus sabdariffa extract; AUC, area under the curve; Cmax, maximum concentration; ${ }^{*}$ Group II/ group I; ${ }^{+}$Lower limit/upper limit.

sabdariffa L. extract has well documented antioxidant activity, which could increase the plasma concentration of GSH [24]. This could in turn increase the formation of a mixed disulfide captopril complex and lower the concentration of free captopril in plasma [25]. Quercetin contained in Hibiscus sabdariffa aqueous extract could reduce the expression of the PEPT1 transporter. The transporter plays an important role in absorption of ACE inhibitor drugs, such as captopril. It therefore could reduce the concentration of captopril absorbed into blood circulation and finally reduce the concentration of free captopril in plasma [26, 27]. Two weeks of coadministration of $H$. sabdariffa extract is sufficient enough to affect the GSH level or the expression of the PEPT1 transporter.

The total number of samples used in this study is limited; therefore, there is a possibility that the effect shown in humans especially when performed in large population will be different. In order to minimize the differences possibility, 
the doses used in this study were extrapolated from the usual doses given to humans. The researcher also applied the refinement procedure during housing and blood collection as explained in the Materials and Methods section to minimize any bias during the study.

\section{Conclusion}

Two weeks of coadministration of $H$. sabdariffa L. extract prior to administration of captopril could affect the pharmacokinetic profile of captopril significantly Therefore, regular consumption of $H$. sabdariffa L. aqueous extracts such as tea should be avoided when taking captopril.

\section{Abbreviations:}

$\begin{array}{ll}\text { ACE: } & \text { Angiotensin converting enzyme } \\ \text { ACN: } & \text { Acetonitril } \\ \text { ANOVA: } & \text { Analysis of variance } \\ \text { AUC: } & \text { Area under curve } \\ \text { BEH: } & \text { Ethylene bridged hybrid } \\ \text { BW: } & \text { Body weight } \\ \text { Cl/F: } & \text { Th apparent total body clearance } \\ C_{\text {max }}: & \text { Maximum concentration } \\ \text { CV: } & \text { Coefficient of variation } \\ \text { DAD: } & \text { Diode-array detector } \\ \text { EDTA: } & \text { Ethylenediaminetetraacetic acid } \\ \text { GSH: } & \text { Reduced glutathione } \\ \text { HS: } & \text { Hibiscus sabdariffa } \\ \text { HCA: } & \text { Hidroxycitric acid } \\ \text { HPLC: } & \text { High-pressure performance chromatography } \\ \text { IS: } & \text { Internal standard } \\ \text { Ke: } & \text { The values of elimination constant } \\ \text { LLOQ: } & \text { Lower limit of quantification } \\ \text { PEPT1: } & \text { Peptide transporter 1 } \\ \text { p.o.: } & \text { Per-oral administration } \\ \text { QCL: } & \text { Quality control sample low concentration } \\ \text { QCM: } & \text { Quality control sample medium concentration } \\ \text { QCH: } & \text { Quality control sample high concentration } \\ \text { SD: } & \text { Standard deviation } \\ T_{\text {max }}: & \text { Maximum time } \\ \text { T1/2: } & \text { Half-life; } \\ \text { UPLC/MS- } & \text { Ultrahigh-pressure liquid chromatography- } \\ \text { MS: } & \text { tandem mass spectrometry } \\ \text { TQD: } & \text { Triple quadrupole detector } \\ \text { Vd/F: } & \text { The apparent volume of distribution. } \\ & \end{array}$

\section{Data Availability}

The data used to support the findings of this study are available from the corresponding author upon request.

\section{Disclosure}

The funding sponsors had no intervention in the design of the study; collection, analyses, and interpretation of data; writing the manuscript; and also the decision to publish the experiment results.

\section{Conflicts of Interest}

The authors declare that there are no conflicts of interest.

\section{Acknowledgments}

The authors have much appreciated the financial support from Directorate of Research and Community Engagement, Universitas Indonesia (QQ 2019 grant).

\section{References}

[1] N. Mahadevan, S. Kamboj, and P. Kamboj, "Hibiscus sabdariffa Linn-an overview," Natural Product Radiance, vol. 8, pp. 77-83, 2009.

[2] M. Haji Faraji and A. H. Haji Tarkhani, "The effect of sour tea (Hibiscus sabdariffa) on essential hypertension," Journal of Ethnopharmacology, vol. 65, no. 3, pp. 231-236, 1999.

[3] A. L. Hopkins, M. G. Lamm, J. L. Funk, and C. Ritenbaugh, "Hibiscus sabdariffa L. in the treatment of hypertension and hyperlipidemia: a comprehensive review of animal and human studies," Fitoterapia, vol. 85, pp. 84-94, 2013.

[4] S. J. Showande, O. M. Adegbolagun, S. I. Igbinoba, and T. O. Fakeye, "In vivo pharmacodynamic and pharmacokinetic interactions of Hibiscus sabdariffa calyces extracts with simvastatin," Journal of Clinical Pharmacy and Therapeutics, vol. 42, no. 6, pp. 695-703, 2017a.

[5] S. J. Showande, C. C. Udoh-Kalu, and T. O. Fakeye, "Pattern of use of water beverage of Hibiscus sabdariffa Linn in a university community in Southwest Nigeria," West African Journal of Pharmacy, vol. 28, pp. 102-111, 2017b.

[6] N. Ezenwanyi, "Interaction of ciprofloxacin and extract of Hibiscus sabdariffa Linn (Roselle) calyses in antimicrobial assays by "agar-well cross-reaction technique," British Journal of Applied Science \& Technology, vol. 15, no. 2, pp. 1-8, 2016.

[7] J. A. Kolawole and A. Maduenyi, "Effect of Zobo drink (Hibiscus sabdariffa water extract) on the pharmacokinetics of acetaminophen in human volunteers," European Journal of Drug Metabolism and Pharmacokinetics, vol. 29, no. 1, pp. 25-29, 2004.

[8] B. M. Mahmoud, H. M. Ali, M. M. A. Homeida, and J. L. Bennett, "Significant reduction in chloroquine bioavailablity following coadministration with the sudanese beverages aradaib, karkadi and lemon," Journal of Antimicrobial Chemotherapy, vol. 33, no. 5, pp. 1005-1009, 1994.

[9] O. O. Ndu, C. S. Nworu, C. O. Ehiemere, N. C. Ndukwe, and I. S. Ochiogu, "Herb-drug Interaction between the extract of Hibiscus sabdariffa L. and hydrochlorothiazide in experimental animals," Journal of Medicinal Food, vol. 14, no. 6, pp. 640-644, 2011.

[10] G. Goutianos, A. Tzioura, A. Kyparos, and V. Paschalis, "The rat adequately reflects human responses to exercise in blood biochemical profile: a comparative study," Physiological Reports, vol. 3, no. 2, pp. 1-9, 2015.

[11] X.-F. Leong, C.-Y. Ng, and K. Jaarin, "Animal models in cardiovascular research: hypertension and atherosclerosis," BioMed Research International, vol. 2015, Article ID 528757, 11 pages, 2015.

[12] S. Paramita, R. Lingua, R. Isnuwardana et al., "Pola penggunaan obat bahan alam sebagai terapi komplementer pada pasien hipertensi di Puskesmas," Jurnal Sains Dan Kesehatan, vol. 1, no. 7, pp. 367-376, 2017.

[13] S. A. Nurfaradilla, F. C. Saputri, and Y. Harahap, "Effects of Hibiscus sabdariffa calyces aqueous extract on the antihypertensive potency of captopril in the two-kidney-one-clip rat 
hypertension model," Evidence-Based Complementary and Alternative Medicine, vol. 2019, Article ID 9694212, 7 pages, 2019.

[14] I. C. Rodríguez-Medina, R. Beltrán-Debón, V. M. Molina et al., "Direct characterization of aqueous extract of Hibiscus sabdariffa using HPLC with diode array detection coupled to ESI and ion trap MS," Journal of Separation Science, vol. 32, no. 20, pp. 3441-3448, 2009.

[15] G. Donáth-Nagy, S. Vancea, and S. Imre, "Comparative study of captopril derivatization reaction by LC-UV, LC-MS and CE-UV methods," Croatica Chemica Acta, vol. 84, no. 3, pp. 423-427, 2011.

[16] E. S. Elzanfaly and H. A. Merey, "A liquid chromatography/ tandem mass spectrometric method for determination of captopril in human plasma: application to a bioequivalence study," Journal of Applied Pharmaceutical Science, vol. 7, pp. 008-015, 2017.

[17] Siska, D. S. Franciscus, M. Abdul, B. Anton, and Priyanto, "Determination of captopril in rat plasma by LC-MS/MS in presence of apigenin," Advance Science Letter, vol. 23, no. 12, pp. 12447-12450, 2018.

[18] S. Vancea, S. Imre, G. Donáth-Nagy et al., "Determination of free captopril in human plasma by liquid chromatography with mass spectrometry detection," Talanta, vol. 79 , no. 2, pp. 436-441, 2009.

[19] D. Nwachukwu, E. Aneke, L. Obika, and N. Nwachukwu, "Effects of aqueous extract of Hibiscus sabdariffa on the reninangiotensin-aldosterone system of Nigerians with mild to moderate essential hypertension: a comparative study with lisinopril," Indian Journal of Pharmacology, vol. 47, no. 5, pp. $540-545,2015$.

[20] D. Ojeda, E. Jiménez-Ferrer, A. Zamilpa, A. Herrera-Arellano, J. Tortoriello, and L. Alvarez, "Inhibition of angiotensin converting enzyme (ACE) activity by the anthocyanins delphinidin- and cyanidin-3-O-sambubiosides from Hibiscus sabdariffa," Journal of Ethnopharmacology, vol. 127, no. 1, pp. 7-10, 2010.

[21] B. H. Migdalof, M. J. Antonaccio, D. N. Mc Kinstry et al., "Captopril: pharmacology, metabolism, and disposition," Drug Metabolism Reviews, vol. 15, no. 4, pp. 841-869, 1984.

[22] A. Zisaki, L. Miskovic, and V. Hatzimanikatis, "Antihypertensive drugs metabolism: an update to pharmacokinetic profiles and computational approaches," Current Pharmaceutical Design, vol. 21, no. 6, pp. 806-822, 2014.

[23] Food and Drug Administration, Bioanalytical Method Validation, Guidance for Industry, Food and Drug Administration, Silver Spring, MD, USA, 2018.

[24] I. F. Usoh, E. J. Akpan, E. O. Etim, and E. O. Farombi, "Antioxidant action of dried flower extracts of Hibiscus sabdariffa L. on sodium arsenite-induced oxidative stress in rats," Asian Network for Scientific Information, vol. 4, pp. 135-141, 2005.

[25] J. H. K. Yeung, A. M. Breckenridge, and B. K. Park, "Drug protein conjugates-VI. Role of glutathione in the metabolism of captopril and captopril plasma protein conjugates," Biochemical Pharmacology, vol. 32, no. 23, pp. 3619-3625, 1983.

[26] T. Zhu, X.-Z. Chen, A. Steel, M. A. Hediger, and D. E. Smith, "Differential recognition of ACE inhibitors in xenopus laevis oocytes expressing rat PEPT1 and PEPT2," Pharmaceutical Research, vol. 17, no. 5, pp. 526-532, 2000.

[27] J. Barrenetxe, P. Aranguren, A. Grijalba, J. M. MartínezPeñuela, F. Marzo, and E. Urdaneta, "Effect of dietary quercetin and sphingomyelin on intestinal nutrient absorption and animal growth," British Journal of Nutrition, vol. 95, no. 3, pp. 455-461, 2006. 